\title{
UNIVERSITYOF
}

FORWARD

THINKING

WESTMINSTER用

WestminsterResearch

http://www.westminster.ac.uk/westminsterresearch

From Cartographic Gaze to Contestatory Cartographies

Specht, D. and Feigenbaum, A.

This is an accepted manuscript of a book chapter published by Routledge in Mapping and Politics in the Digital Age on 6 November 2018, available online:

http://www.routledge.com/9780815357407

The WestminsterResearch online digital archive at the University of Westminster aims to make the research output of the University available to a wider audience. Copyright and Moral Rights remain with the authors and/or copyright owners.

Whilst further distribution of specific materials from within this archive is forbidden, you may freely distribute the URL of WestminsterResearch: ((http://westminsterresearch.wmin.ac.uk/)).

In case of abuse or copyright appearing without permission e-mail repository@westminster.ac.uk 


\section{From Cartographic Gaze to Contestatory Cartographies}

Doug Specht and Anna Feigenbaum

\section{Cartographic Gaze}

Rene Descartes declared in the $16^{\text {th }}$ Century that the world was now dominated by the visual, a notion that would be seen as defining the Enlightenment (Descartes, cited in Potts, 2015). As the increased dominance of seeing and the desire to visualise the world cohered with the production of increasingly accurate tools of measurement and the advent of the printing press, cartography emerged as a discipline, often used as tool of oppression and dominance. Cartographic visualizations, afforded the creator, and user, a Gods eye view of the world. Following others (See Casas-Cortés et. al., 2013; Koch, 1998), this chapter refers to this way of seeing the world from above as the Cartographic Gaze. First, the chapter briefly examines the historical emergence of the Cartographic Gaze before turning to a discussion about how the proliferation of geographic imaging technologies and digital tools simultaneously further embedded this gaze into mapping practice, while also diffusing such practices of mapping to broader populations. Discussing the rise of participatory mapping and counter mapping under the rubric of contestatory cartographies, the chapter presents some of the challenges that face those attempting to create alternative maps of their worlds, and the ways in which they become entrapped by the pervasiveness of the Cartographic Gaze. We use the term participatory mapping to refer to methodologies for map-making based around the participation of those who the map will represent. And we employ the term counter mapping to reference those mapping practices that explicitly seek to expose and challenge power relations. In specific, we look at how the colonizing origins of the Cartographic Gaze limit what it is possible to do with these alternative mapping practices.

\section{The Emergence of the Cartographic Gaze}

While maps have long been used by states as tools of control, a theme that can be traced back to the Babylonians (Finkel, 1995), the $16^{\text {th }}$ Century saw this on an unprecedented 
scale. Newly 'discovered' lands required an increasingly detailed series of mappings. These maps were produced as views from above and worked to serve as tools of possession, the explorer and cartographers' elevated position and the commanding view provided by the maps mirrored the divine gaze of God, positioning the commissioner of the map in a seemingly omniscient position (See, further, Lobo-Guerrero's chapter). In this way, the Cartographic Gaze was the precursor to the surveillant gaze, epitomized by Bentham's Panopticon and the work of Foucault. These new maps of the Sixteenth Century allowed for increased control, and far reaching power on behalf of the monarchs and landowners they served. Ownership over space became defined in robust terms, and alongside the process of enclosure, the position of the peasantry, landowners and the Monarchy became ever solidified, changing the perception and understanding of space itself. Furthermore, the Cartographic Gaze also embodies the Sartrian conceptualization of Gazing, serving as another battlefield for the definition of self. This becomes particularly prevalent in the use of maps as colonial objects where God-like views of the world are used to carve up new territories, define peoples, resources and power across newly 'discovered' territories.

These maps were instrumental in the forming of the Other, and with that the subjugation of the Other. The Cartographic Gaze objectifies the Other and robs one of freedom as a subject (Sartre, 1963; Yancy, 2008). Much like the gaze of Medusa that turned the onlooker to stone, the map solidifies relations and immobilizes those who are mapped. In the Sartrian sense, the Cartographic Gaze then is not a way of looking at the world, but a medium for spreading domination through power models emboldened through colonialism. This positions the map maker in a divine position and strips the mapped of their selfdetermination, limiting insurrection. To take this Sartrian tone further; it is 'nothing but an ideology of lies, a perfect justification for pillage; its honeyed words, its affectation of sensibility [are] only alibis for aggression' (Sartre, 1963: 21). 
Furthermore, the Cartographic Gaze proliferated the illusion of accuracy in maps and data. Wood (2015) argues that 19th century empiricism imbued maps with the myth that what they visualised were 'veridical and value-free pictures of reality' (n.p.). It was also during this time that charts came into what Friendly (2008) calls the Golden Age of Statistical Graphics. The rise of statistical offices that came with the use of quantitative and numerical information for industrialisation and commerce, gave way to a range of graphical developments for representing statistical information. While used primarily by government institutions, this period also saw the employment of these techniques in social campaigns, including Florence Nightingale's rose diagram on preventable deaths in the Crimea War (See Brasseur, 2005). More often cited in geographic circles is John Snow's (1855) cholera maps, which, while rarely held up as such, actually stand as a testament to the illusion of the accuracy of maps Instead they are referenced by those wishing to perpetuate the myth of maps alone being able to save lives, while the reality was that these maps were neither revolutionary, nor were they instrumental in persuading others (See Specht, 2017; Shapter, 1971). The myth surrounding these maps has become increasingly prevalent throughout modernity, perpetuating the notion of accuracy provided by these exercises, and helping to solidify the same and Gaze that allowed for their development.

The power to map - as with the power to collect, analyse and visualize statistical information - rested largely in government and large-scale corporate organisations. Yet the power of the cartographic gaze is not restricted to those in positions of authority. With the rise and spread of digital tools for mapping and open data at the end of the $20^{\text {th }}$ century, the modes of seeing derived from the Cartographic Gaze became embedded in new tools. These reinforced the illusionary vision of the Cartographic Gaze, yet also diversified and expanded who could participate in the manufacture of this gaze. This expansion of the power to map calls for a more complex understanding of the history and function of the Cartographic Gaze that does not simply pit visualisation's empirical and imperial power against critical critiques of these practices as inherently oppressive. What is needed instead is a better way of documenting 
how the power of visualisation has been embedded, distributed and tactically put to use by different parties in struggles for social equality and justice. Geography and Communication Studies have offered up a number of such ideas over the last hundred years, with themes of participatory mapping and counter-mapping practices being prevalent, although these attempts are far from homogenous in their ideas.

\section{Contestatory Cartography}

The connections between the datafication of peoples, data visualization and cartography while born in the $19^{\text {th }}$ Century, were solidified with the advent of Geographic Information Systems (GIS) technologies. GIS systems have been around since the 1960s, and can even be traced back to the early days of computing in the 1950s when the military began to see the importance of connecting geography with the new power of computing (Hacklay, 2010). Esri', one of the most powerful mapping companies in the world emerging in the 1970s, and software, that would allow personal computers to harness GIS products, appeared in the 1980s. The 1990s saw huge developments in computing and computing power, leading to the emergence of companies such a Garmin (est. 1989) and the development of ever more powerful GIS and GPS (Global Positioning System) based programmes. Yet these systems, and their processes of codification and datification of people remained tools of the elites, continuing to extend the Cartographic Gaze through now digital means. The level of complexity and multi-disciplinary knowledge required to operate them, and interpret their data, was too significant a barrier to entry. The vast amounts of computing power required and until the early 2000s, limited access to the data required - meant that not only were the barriers too high, but also that the only way to enter the market was through connections to the military or state, for example Ordnance Survey in the UK (Evans, 2013). Thus, these maps also represent the power held within these institutions (Ballatore, 2014), something which is still prevalent.

\footnotetext{
${ }^{1}$ Formally known by its full title, Environmental Systems Research Institute.
} 
More recent changes in web-based geo systems and open source GIS have begun to reduce both the technical and financial entry points into digital map making (Goodchild, 2009). In the late 2000s emergent digital interfaces became more and more accessible, giving rise to what has been popularly called 'cartography 2.0' (Crampton 2009), our current period of cartographic production that has seen a proliferation of digital mapping. The proliferation of digital mapping platforms and related tools has meant that access becomes cheaper and intermediaries are not always required to call, invite, edit or prescribe what cartographic artefacts will be produced. Distinct from more general practices of 'cartography 2.0,' contestatory cartography involves a direct engagement with the ethics and risks that arise in the process of cartographic production. Drawing from PGIS and activist mapping practices from previous decades, 'cartography 2.0 ' brings with it new and adapted practices of cartographic production as people experiment with ways to try to contest sites and practices of colonial power through mapping. This often involves mappings that make social and economic injustices visible, contest spatial rendering of resources done by authorities, or challenge statistical analysis related to spatial boundaries.

Casas-Cortes and Cobarrubias (2008) note that there has been an increase in people around the world who are engaging these new technologies to draw 'new maps, maps of resistance that can be used to attack the visible and invisible around them' (60). By then using these maps as part of the process of advocacy involves and explicit recognition of maps as rhetorical devices. In this way, maps no longer solely represent space, but instead they are used to shape the direction of the argument, to identify those objects to be considered, and to also lay out the discursive boundaries of the discussion. 'When individuals make their own maps, they offer an expression of what they consider important, what they consider to be "of interest", and for what they are willing to fight' (Institute for Applied Autonomy, 2008: 35). So, the thinking goes, those who make their own maps are able both to lay claim to landscapes, and position themselves within the narrative as both authors and individuals. In this way, these new cartographies, it is suggested, offer a direct 
challenge to the perceived neutrality of spatial data. By confronting this power, map makers can claim their right to set the rules of debate and to provide interpretations with both 'an authority and a contingency equal to official representations' (ibid.: 35).

However, while these tactical cartographies may be able to amplify voices, change conversations and influence policies, their experimentation is still bound by the Cartographic Gaze. The new resources 'cartography 2.0' offers up, which include Google Earth and Google Maps, were first built upon newly available military satellite data - introduced in 2005 (Crampton, 2009). While this allowed for mappings of alternative visions of society (Evans, 2013), the colonial logics of cartographic vision itself are much harder to transform. These broader questions around the limitations and possibilities for what contestatory mapping can do are beginning to open-up critical debate around the relationships of power and space and the new knowledges that might inhabit these spaces (Bryan, 2011; Parker, 2006). In the remainder of this chapter we discuss two primary-and sometimes overlapping-modes of contestatory mapping, participatory mapping and counter mapping, before turning to look at some of the ways that the cartographic gaze remains embroiled in these contestatory practices.

\section{Participatory Mapping}

In the 1980s new modes of using GIS came to be called many things, most of which fall under the umbrella of PGIS or PPGIS (Participatory-GIS, and Public Participatory-GIS respectively). PGIS in itself has a rich and diverse conceptual history drawing upon PRA (Participatory Rural Appraisals) development methods, community planning and development practices, critical theory and political economies (Weiner et al., 2002; Harris, 2016). In the last decade PGIS has built a new foundation based upon a better understanding of the political and institutional conditions of GIS itself and now seeks to foster ever more inclusive practices. However, it still represents only one genus of the 
rapidly developing mass of geographic tools for public use (Elwood, 2006; Walker and Rinner, 2013).

While the history of participatory mapping can be traced back to the PRA movement of the 1980s, it is becoming clear that the wide range of online tools and the bringing together of the web 2.0 and GIS into the GeoWeb has brought about a whole new way of working with participatory systems. Along with these new practices, a range of new debates and epistemologies have emerged, which might be thought of as neogeographies (Crampton, 2009; Atzmanstofer et al., 2014). Connecting these PGIS elements to mobile devices and their inbuilt GPS, people become used as censors to further enable the creation of crowd sourced participatory maps (Sheehan, 2015; Meek et al. 2014). Projects such as OpenStreetMap have shown what can be achieved by amateurs with little or no geographic background (Goodchild, 2009). Even before such enterprises, Jane Goodall had seen the benefits of satellite images for conservation, even based on low resolution aerial photography (Tullis, 2015). Médecins Sans Frontières have stated the importance of maps and participatory mapping projects in helping them to reach people in times of crisis (Smith, 2015).

Moreover, participatory mapping activities are helping communities to lay claim to land around the world (Johnson et al., 2005), notably the peoples of Awas Tingni and the Maya of Belize who have significantly changed the legal status of indigenous peoples in the region (Wainwright and Bryan, 2009). PGIS has been used to support the United Nations Programme on Reducing Emissions from Deforestation and Forest Degradation (UNREDD), healthcare, targeting villages for development aid and forestry projects and in protests against water contamination from large scale mining projects (Eisen, 2014; Catlett and Ghani, 2015; Specht, 2018). Community led PGIS projects have also helped WaterAid to invest appropriately in the poorest areas of Dar es Salaam, leading to significant improvements in the lives of people there (Gloeckner et. al., 2004). Furthermore, PGIS, 
through its inclusion of the communities affected by map-making practices has been shown in some cases to reduce conflict and help communities arrive at collective decisions (Carver, 2003). And the diffusion of GIS through the web now means that it is possible to both reach more places and work remotely with communities, or even bring remote communities together in a share digital space (Elwood, 2006).

These are all significant initiatives and achievements which should not be discounted, but nor should they been seen in isolation of the bigger (P-)GIS narrative. The assumption that PGIS projects automatically promote empowerment and the bringing together of communities is dangerous and naïve (Weiner et al., 2002). The basic entry requirements for GIS have not actually moved all that much-- fast internet, a computer or tablet are still required for producing the maps themselves. Even if a mobile phone is sufficient for some tasks, large data centres and increasingly large amounts of computing power is needed to crunch the data produced by these phones. This means that the control over the data produced has not been wrestled from the hands of the elite hands in the way that PGIS and neogeography scholars have suggested (Haklay, 2013). Furthermore, there is the issue of participation in its broadest sense, with all the cultural and social implications that this brings and the balances of power that it might upset or bring to light (Sletto, 2009). These kinds of participatory projects can serve not to diminish, but rather to reinforce the dichotomy between local and scientific knowledge, and so are less of an insurrection than a disempowering exercise (ibid.).

Yet, geographers often celebrate the power of participatory maps and activists like Nietschmann, Brody, Herlihy, Stocks, Chapin, and Harris. In these numerous conceptualisations, the basic understanding of these PGIS projects tend to see the practice as replacing bad colonial maps with good anti-colonial ones. Yet, it is clear that these new maps are neither inherently good nor beyond question; they are open to multiple readings, and they may have potentially undesirable outcomes. Accordingly, there is required analysis 
of the social processes through which participatory maps are produced and read (Wainwright and Bryan, 2009). It would seem then that the way in which neogeographies and PGIS practice have evolved to detach PGIS from its background in GIS (Weiner et al., 2002) is problematic. It is also clear that the average citizen is not aware of the body of knowledge that rests behind more traditional mapping practices practice, and the critical discourses that challenge the Cartographic Gaze (Goodchild, 2009). This is compounded as research around GIS and PGIS has too become increasingly removed from the critical discourses of the 1990s, as scholars struggle to keep up with technological advances and the increasing numbers of people who are engaging with these tools. To counter this, it is important to approach PGIS as a spatial practice that reframes societies rather than just remaps them (Bryan, 2011), in the same vain, PGIS should not be examined as a tool that can be picked up and then put down again, rather these mappings become an intrinsic part of the fabric of everyday life (Johnson et. al, 2005). It is certain that the role of citizens has shifted greatly from being the object of maps to being the creator of maps, but this has not turned maps into neutral objects separated from power (Pánek, 2016).

While PGIS is on the increase, it will be sometime before the last billion are connected to the internet, thus any representation will always exclude them (Verplanke et al., 2016). Maps certainly already colonize the imagination, and it is essential then to ensure they do not continue to colonize or subjugate those who are being mapped, through the obscuring guise of PGIS and data visualization (Bayley, 2016). This though, is difficult to escape, even the great cartographic theorist Brian Harley has expressed somewhat of a personal outrage that he himself might have been duped by such maps and visualizations, which, he later came to note, were more destructive that guns and warships in their power to oppress the Other and to crush insurrection against anything but the map's representation of power (Harley, 2002). This perhaps leaves us once again impotent to enact change or to challenge power through these tools. After all, the participatory element of PGIS is in many ways little more than an 
addition, both semantically and in practice, to the imperialist juggernaut of military derived Geographic Information Systems.

\section{Counter Mapping}

The inaccuracy, bias or total lack of representation that can be found in maps, has lead people to argue that we need to draw new maps, maps of resistance that can be used to attack the visible and invisible (Casas-Cortes and Cobarrubias, 2008). This invisibility and lack of representation is not just an issue in the developing world. Across Europe, there are places and people that cannot be found on regular maps, from Italy to Great Britain and beyond the border of Schengenland in Romania, Ukraine, Libya and Morocco, migrants, undocumented peoples, non-conformist religious sites, non-nationalized languages and ethnic groups are not mapped, or are removed from maps. Counter maps then are maps of resistance that go beyond the notions of participation and the theoretical barriers of PGIS. While participatory mapping practices involve local or affected communities, they use traditional, institutional models and modes for mapping, often led by an outside practitioner. Whereas counter-maps seek to subvert both the methodological practice of mapping and to expose and challenge power relations; to question at its core the Cartographic Gaze. Taking on a variety of forms, counter-maps work to challenge the status-quo and disrupt normative ideas of place and space, often seeking to remove or undermine the Cartographic Gaze. Distinct from more general uses of mapping or PGIS, counter-mapping involves an explicit engagement with the ethics and risks that arise in the process of making maps together. This often involves critical analysis of how people, and the places they inhabit, become represented.

This kind of counter-mapping can open up possibilities for new forms of knowledge production and political change. Furthermore, counter-mapping develops the notion that technologies in themselves cannot be of use without developing meaningful relationships around knowledge and power sharing. Counter-mapping then might be seen as a direct 
response to the top-down elitist, colonial mapping embodied by the Cartographic Gaze, bringing together a new collective order which will better represent the people who are being mapped and producing the map (Parker, 2006). Although counter-mapping has to some extent been regularly practiced in the developing world (Perkins, 2007) there are increasing opportunities for more mapping practice to occur, potentially allowing for a greater empowerment of communities and the amplification of stories (Weiner et al., 2002). The world has become increasingly spatially orientated (Soja, 1989). Understanding that maps are filled with signs and myths helps us to better understand the information or data held within the map, and thus who is represented or not, and from this it is possible to create counter-mapping projects. Just as the photographer must make a number of choices of framing, point of view, lenses, lighting, film, speed, plus the choices in the darkroom, so too does the mapper and the counter-mapper as they map the knowledge preferred by them (Gripsrud, 2006). This notion that even the counter maps must, by definition of space, also make such choices about what is included, and more importantly who is excluded, leads to significant limitations of these contestatory cartographies.

\section{Limitations of Contestatory Cartography}

Much of the discussion around PGIS and counter mapping suggests that people no longer have to settle for representations being imposed upon them; as access becomes cheaper, making a self-representation no longer requires intermediaries to call, invite, edit or prescribe the way in which cartographic representations are produced. In the digital age, it is perhaps possible to escape the Cartographic Gaze as people no longer need a broadcaster to provide a platform, to invite, or to edit their self-representations (Thumim, 2012). Yet, despite all of these many claims for the benefits of self-representation 'to this day many groups, communities and individuals consider themselves to be dangerously misrepresented' (Kidd, 2016: 8). The virtues of participatory GIS and counter mapping cannot alone erode the conflict between what Barthes (1957) would term the denotations and the connotations of the cartographic artefacts. Because mapping is most often a process that 
combines aerial visual representation (or a view from above) with data and geographical information, these alternative maps remain embedded in the practices that emerged out of the colonial agenda. They cannot escape their embodiment of military technology and the pervasive Cartographic Gaze with its historical roots as a practice of containment, persuasion and oppression. These impossibilities of escaping the Cartographic Gaze can be broadly seen in three areas: firstly, that platforms have politics; secondly that the visualization practices involved in the creation of maps is never neutral; and thirdly, that all maps are only a partial perspective of the landscape they represent, and the experiences of the people that inhabit that landscape. The remainder of this chapter will examine each of these limitations in turn.

\section{Platforms have politics}

Following new media scholars, platforms can be considered as computational software that offers affordances and limitations to users' participation and interactions. The 'politics' of a platform refers to how power gets embedded into computational layers, as well as how relations play out through user engagement with the platform (Gillespie 2010, Helmond 2015, Langlois \& Elmer, 2013). Mapping platforms, while less often considered by new media scholars, are sites at which decisions around programming, often hidden from users, are deeply embroiled in politics. As mapping platforms often pre-determine places and their meanings, they shape users' spatial imaginations and limit what is possible to map.

As noted above, the rise of digital mapping platforms was born from firstly the colonial roots of the Cartographic Gaze of the enlightenment era, through the military development of GIS, computing and satellite technologies, and then on to participatory platforms. Whether elite or lay produced, all mapping, even that which aims to counter the status quo, is based upon classification and codification of real world objects into taxonomies and terminology. The slots into which data might be fitted are defined by those who make the software, not those who create the knowledge (Brown et. al., 2013). For a long time the knowledge of local 
peoples has been translated through tools and language to suit the needs of the colonizer (Kitchin et al., 2009), resulting in mapping platforms that resemble or make programmable the coloniser's renderings of place and space. While the more collaborative approaches of PGIS may attempt to re-prioritise local and minoritarian spatial knowledges, this knowledge becomes mediated through tools invented by the military at the height of colonial worldviews (Harris, 2016; Elwood, 2006; Carver, 2003). This is something that occurs at the very level of translation from subjugated knowledge into Western information, particularly in relation to the often flexible, porous nature of indigenous understandings of land, and the hard lines of scientific maps and their taxonomies (Harris, 2016). In this sense, some argue that PGIS and counter-mapping can provide little more than a simulacrum of subjugated local and indigenous knowledges (Rundstrom 1998).

This colonial translation can manifest politically. Zoom into the disputed areas between Palestine and Israel on OpenStreetMap and you will find the city of Jerusalem, named in Hebrew. A few years back, zooming in the area could yield results in Arabic or Hebrew, depending on which of the community's mapping warriors - a term used to describe those who engage in such online mapping conflicts - had most recently updated their wiki style database. The OpenStreetMap team, to stop the constant changing of the city's name locked the database, decided to follow a policy of naming in favour of what they call the 'dominate controlling power' in a region. The open platform, designed for participation, for countering the dominant structures in global mapping becomes compromised by its coding, and by the pervasive nature of global politics.

This kind of platform politics can be found across other similar incidents. In Crimea, as the Russians rename cities and streets, OpenStreetMap must decide who the dominant power is. Related occurrences have appeared on Google Maps, which allows for public participation in naming places and updating data. In 2011, as rebels advanced on Gaddafi in Libya, Green Square was returned to its pre-Gaddafi era name of Martyrs Square. Maps 
don't just reflect conflicts on the ground; their power can shape territorial disputes. In 2010 Nicaragua accidentally invaded Costa Rica because of a Google Maps error that placed the border in accordance with an outdated 1858 treaty. Quite what the Nicaraguan army were doing relying solely on Google Maps, is another question. Even when making counter-maps, it is not possible to escape these platform politics. As Sean Cubitt reminds us, while computers will talk to anyone, it is the privileged and historically powerful that teach them to speak.

\section{No visualisation is neutral}

Like all visual representations, maps capture, construct and communicate meaning.

Questions of how best to visually represent places, quantities, topical issues, experiences, or anything else that you have decided to map will always be fraught with debate. Just as platforms can have political decisions embedded in them, so too can the software and visual libraries people use to create the visual interfaces and symbology of maps. The development of ISOs, international treaties on mark-up language, symbology and database structures of geographic information embed the cartographic gaze into the visual representation of spatial information. While this consistency of forms can help build literacy through repetition, and ensures compatibility across platforms, it also privileges particular ways of seeing data and reifies the idea that visualisations are objective representations of the truth. Likewise, the statistical visualization conventions developed in the 19th century continue to be used by data visualisation designers. Visualisation libraries (for example D3.js), as well as software programmes that simplify the generation of visualisations from raw data (for example Tableau), further embed these conventions into contemporary digital map design, and often without the user being able to see or access the process of visualisation, leading to a reduction in the space for critical analysis of this work. To take a rather basic example, Google's decision to give over more space to the mapping of roads, and the make these a more prominent and detailed feature of it's service does well in helping navigation, but this presentation of data also skews the viewers perceptions of the 
importance, and quantity of roads, while at the sometime diminishing the presence of people and cities. While this this might seem like a harmless issue, but to incorporate the additional road labels, the names of urban centres have been removed, effectively eliminating their existence (O'Beirne, 2016). The complications are numerous even with relatively simple scenarios. The issue as ever comes back to the question of who decides which categories, colours and logos are legitimate, representative or appropriate. Even if this power to label is turned over to participants, one person's deforestation issue can be another person's indigenous rights issue.

Attempts to confront and challenge these limitations can be found in contestatory mapping projects, particularly those that engage explicitly with the aesthetics of map production. Art maps that break conventions and sense maps that challenge the dominance of the visual, are some strategies that seek to confront the Cartographic Gaze. These mapping practices attempt to reveal the Cartographic Gaze's oppressive history and binary assumptions, thus undoing the apparent neutrality they avow (D'Ignazio and Klein 2016, Lupton 2017). For many critical cartographers, tensions exist between this desire to challenge the cartographic gaze, yet still produce a map that is easily readable and understandable to audiences. Breaking conventions means taking the user outside of how they are trained to see. While this can yield affective moments and transformative encounters, it may also distract from the delivery of the maps messages. What strategies contestatory cartographers choose rests on considerations of audiences and desired outcomes.

\section{Problem of Partial Perspectives}

If it were possible to overcome the limitations related to platform politics and visualisation, then the barrier of perspective is all but impenetrable. As Branston and Stafford (2010) note, 'no representation can contain more than a fraction of its real-world subject' (129). No map, counter, participatory, military or otherwise, can be a perfect depiction of territory, in fact for a map to be a truly faithful representation of space, it would need to be at a scale of $1: 1$, 
including every feature of the land at correct scale; this feat has only been achieved in fiction, in Borges' $(2000 ; 1960)$ celebrated story On Exactitude in Science. And thus, something must give, something must be left off; when people create representations of the world there are agendas at play and a particular set of ideas, values, attitudes and identities become normalized. These appear as issues of power, ownership, authenticity and meaning (Kidd, 2016). As the Car-Tac Collective wrote, 'even [if] the map is not the territory, to make maps is to organize oneself, to generate new connections and to be able to transform the material and immaterial conditions in which we find ourselves immersed. It isn't the territory, but it definitely produces territory' $(2008,64)$.

Even more problematic, those items, be they people, objects, data or locations, that do make their way on to a map, having been seen as a legitimate representation by the cartographer, do then themselves rarely, if ever, have any one single, fixed and unchanging meaning (Hall, 1997). In other words, while the map may appear representational in the mind of the creator, it can only ever be as representative as the viewer, or reader, of the map understands it to be. In this way representation further becomes 'a site of active political, cultural and social movement within which are, each and every one of us implicated' to further echo Stuart Hall (1997: 343). First asked by the Institute of Development Studies (IDS) in 1979 , this predicament is perhaps captured best by the now infamous question; 'Whose Knowledge Counts?'. Regardless of the completeness of a map, the deeply embedded Euro-American, industrial-military, colonial Cartographic Gaze means that data that already conforms to this worldview is what gets taken seriously, or given legitimacy (McFarlane, 2006). This evokes the work of Spivak (1988) when she questions if the subaltern can speak. To fully understand the way in which we understand the Other - or in this case collect and analysis data about the Other - we must turn the anthropological gaze on ourselves. To view our representations about, or on behalf of, the Other as a function of our geopolitical and institutional positioning (Kapoor, 2005). 
Mapping maps onto other maps can help us see these new stories emerge, both from where data overlaps, as well from the holes and cracks that can become clear through these combined visualisations. In this methodology, all competing narratives are mapped together as equals. This can only work, however, if subjugated knowledges, and the Other, are recognized and incorporated as legitimate and comparable, regardless of the way in which they are formed (Balit, 2012; Mosse, 2001; Taylor, 2007). Knowledge must not be provincialized, nor passed off as universal (Robinson, 2003). This becomes an increasingly difficult task within the Cartographic Gaze. First, there is a bias towards the creation of God's eye views of the world, which frequently excludes other interpretations and understanding of existence that may not be considered as 'proper maps'. Secondly, a deep examination of the Gaze must be undertaken to avoid the transference of unresolved conflicts onto any new contestatory mapping projects. Without deep examinations of these conflicts and the Gaze there runs the risk that all attempts to create counter-maps that follow traditional cartographic perspectives become co-opted by the Cartographic Gaze, and all those that reject the traditional cartographic perspectives are themselves rejected at not legitimate representations of space. To allow this, is to pass on own failings unwittingly upon the subjugated once more (Kapoor, 2005).

Finally, a third major issue here is that mapping maps onto other maps still falls to the same creators under this guise. The same issues arise around the control the maps, ownership over the computing power required to aggregate collected data sets and knowledges, and around who is seen as a legitimate person or company to carry out such work. These issues mean that in mapping maps onto other maps the alternative narratives of counter-maps can be assumed within a new map, developed from a less critical position, and thus the alternative narrative can become occluded, by the illusion of completeness that comes with drawing together multiple datasets. This concern once again can leave us feeling trapped and suggests that there is no way out from the limitations of the Cartographic Gaze. However, this is not meant as an argument for a retreat into a simple localism (Ellerman, 
2002), instead it calls for a change in cartographic practice. Such an engagement, however, must counter the unequal power relations, must seek to eliminate the Cartographic Gaze and must move beyond a liberal conception of integrating subaltern knowledge as an addition to Western knowledge. Instead, a more radical conception is needed. While mapping maps and competing knowledges together is of the upmost importance, and something which can draw conflict to the fore (Robinson, 2003), the appropriation of subaltern knowledge must be avoided, Spivak (1988).

\section{Conclusion}

Late twentieth century communication and information technologies have produced such a blurring of what is real and what is representation than the two can no longer be distinguished (Corner, 1999). Maps, be they cartographic, data visualizations, participatory or counter, all sit in this space in-between the virtual and the real. Here Winnicotts question on maps becomes salient in relation to data: did you find the world or did you make it up? The use of geographic information has changed dramatically in the past decade and continues to do so. The platforms and related tools available to make maps are important factors impacting geographic information use and counter-mapping narratives (Brown et. al., 2013). In practice though, PGIS and counter-mapping remain limited in their emancipatory potential. In the developed world, it has been largely subsumed into the burgeoning literature around participatory GIS. PGIS aspires to deliver a more democratic spatial governance, but the majority of this work still emphasizes the incorporation of local voices into maps produced and controlled by specialists, and articulating their agendas, rather than subverting mapping, or changing what is mapped (Perkins, 2007). Counter-mapping has gone some way to challenge this, but the transformation is far from complete.

This chapter has sought to explore the issue of the Cartographic Gaze and the various modes that might enable its deconstruction, through counter-mapping, PGIS and contestatory cartographies. Each of these have been shown to have their limitations in 
relation to the cartographic gaze. This is hardly surprising when considering the notion that all representations have their failings. In pointing out these limitations, our intention is not to suggest that these new modes of working should be abandoned. Instead it serves as a call to question at every turn, every representation. It is well known that this is required, yet terms like participatory and contestatory, or mashup and counter-maps, all too easily lure the creator and reader towards forgetting the in-built biases of the platform, the coding, the symbology the creator and the reader that are tied up in the inescapable, yet very much challengeable, Cartographic Gaze.

\section{References}

Atzmanstorfer, K., Resl, R., Eitzinger, A., \& Izurieta, X. (2014). The GeoCitizen-approach: community-based spatial planning-an Ecuadorian case study. Cartography and geographic information science, 41(3), 248-259.

Balit, S. (2012). Communication for development in good and difficult times. Nordicom review, 33(Special Issue), 105-119.

Ballatore, A. (2014). Defacing the map: Cartographic vandalism in the digital commons. The Cartographic Journal, 51(3), 214-224.

Barthes, R. (1972). Mythologies. 1957. Trans. Annette Lavers. New York: Hill and Wang, 302-06.

Bayley, S. (2016) Maps are as much about art - and lies - as science. Spectator [Online] Available from: https://www.spectator.co.uk/2016/10/maps-are-as-much-about-artand-lies-as-science [Accessed May 2017].

Borges, J. L. (2000; 1960) The Alepha. London and New York: Penguin

Branston, G., \& Stafford, R. (2010). The media student's book (5th Edition). Psychology Press.

Brasseur, L. (2005). Florence Nightingale's visual rhetoric in the rose diagrams. Technical Communication Quarterly, 14(2), 161-182.

Brown, M., Sharples, S., Harding, J., Parker, C. J., Bearman, N., Maguire, M., ... \& Jackson, M. (2013). Usability of geographic information: current challenges and future directions. Applied Ergonomics, 44(6), 855-865.

Bryan, J. (2011). Walking the line: Participatory mapping, indigenous rights, and neoliberalism. Geoforum, 42(1), 40-50.

Carver, S. (2003). The future of participatory approaches using geographic information: Developing a research agenda for the 21st century. Urisa Journal, 15(1), 61-71.

Casas-Cortes, M. and Cobarrubias, S. (2008) Drawing Escape Tunnels through Borders: Cartographic Research Experiments by European Social Movements. In Mogel, L. and Bhagat, A. (eds) (2008) An Atlas of Radical Cartography. Los Angeles: Journal of Aesthetics and Protest Press.

Casas-Cortés, M., Cobarrubias, S., \& Pickles, J. (2013). The cartographic gaze, new cartographies of the border, and the responsibility of mapping. Géoesthétique. 
Coproduced by the Parc Saint Leger (art center), High School of Fine Arts of Clermont-Ferrand, the CNL (National Center of Books), and the CNAP (National Center of Contemporary Art). Paris: B42 Publishers.

Catlett, C., \& Ghani, R. (2015). Big Data for Social Good. Big Data. Vol. 3, No. 1

Corner, J. (1999). The agency of mapping: speculation, critique and invention (pp. 213-252). na.

Crampton, J. W. (2009). Cartography: maps 2.0. Progress in Human Geography, 33(1), 91100.

D'Ignazio, C., \& Klein, L. F. (2016). Feminist data visualization. In Workshop on Visualization for the Digital Humanities (VIS4DH), Baltimore. IEEE.

Eisen, J. (2014) New Community Mapping Innovations could have far Reaching Implications for Forest Governance in the Congo Basin. Mapping for Rights [Online] Available from: http://blog.mappingforrights.org/?p=946 [Accessed March 2015].

Ellerman, D. (2002). Should development agencies have Official Views?. Development in Practice, 12(3-4), 285-297.

Elwood, S. (2006). Critical issues in participatory GIS: Deconstructions, reconstructions, and new research directions. Transactions in GIS, 10(5), 693-708.

Evans, L. (2013). How to build a map for nothing: Immaterial labour and location-based social networking.

Finkel, I.L. (1995) A join to the Map of the World: a notable discovery. British Museum Magazine: the-5 (Winter) pp. 26-27

Friendly, M. (2008). The golden age of statistical graphics. Statistical Science, 502-535.

Gillespie, T. (2010). The politics of 'platforms'. New media \& society, 12(3), 347-364.

Gloeckner, H., Mkanga, M., \& Ndezi, T. (2004). Local empowerment through community mapping for water and sanitation in Dar es Salaam. Environment and Urbanization, 16(1), 185-198.

Goodchild, M. (2009). Neogeography and the nature of geographic expertise. Journal of location based services, 3(2), 82-96.

Gripsrud, J. (2006) Semiotic: Signs, Codes and Cultures. In Gillespie, M. and Toynbee, J (ends) (2006) Analysing Media Texts. New York: MaGraw Hill. 9-42

Haklay, M. M. (2013). Neogeography and the delusion of democratisation. Environment and Planning A, 45(1), 55-69.

Haklay, M. M. (Ed.). (2010). Interacting with geospatial technologies. John Wiley \& Sons.

Hall, S. (1980). Cultural studies: Two paradigms. Media, Culture \& Society, 2(1), 57-72.

Harley, J. B. (2002). The new nature of maps: essays in the history of cartography (No. 2002). JHU Press.

Harris, T. M. (2016). From PGIS to Participatory Deep Mapping and Spatial Storytelling: An Evolving Trajectory in Community Knowledge Representation in GIS. The Cartographic Journal, 53(4), 318-325.

Helmond, A. (2015). The platformization of the web: Making web data platform ready. Social Media+ Society, 1(2), 2056305115603080.

Institute for Applied Autonomy (2008) Tactical Cartographies. In Mogel, L. and Bhagat, A. (eds) (2008) An Atlas of Radical Cartography. Los Angeles: Journal of Aesthetics and Protest Press.

Johnson, J. T., Louis, R. P., \& Pramono, A. H. (2005). Facing the future: encouraging critical cartographic literacies in indigenous communities. ACME: An International Journal for Critical Geographies, 4(1), 80-98. 
Kapoor, I. (2005). Participatory development, complicity and desire. Third world quarterly, 26(8), 1203-1220.

Kidd, J. (2016) Representation. London and New York: Routledge.

Kitchin, R., Perkins, C., \& Dodge, M. (2009). Thinking about maps. Rethinking maps: New frontiers in cartographic theory, 1-25.

Koch, M. (1998). Ruling the world: the cartographic gaze in Elizabethan accounts of the New World. Early Modern Literary Studies, 4(2), 3.

Langlois, G., \& Elmer, G. (2013). The research politics of social media platforms. Culture Machine, 14

Lupton, Deborah. "Feeling your data: Touch and making sense of personal digital data." New Media \& Society 19, no. 10 (2017): 1599-1614.

Macfarlane, R. (2008). Mountains of the Mind: A History of a Fascination. Granta.

McFarlane, C. (2006). Knowledge, learning and development: a post-rationalist approach. Progress in Development Studies, 6(4), 287-305.

Meek, S., Jackson, M. J., \& Leibovici, D. G. (2014). A flexible framework for assessing the quality of crowdsourced data.

Mosse, D. (2001). People's knowledge', participation and patronage: Operations and representations in rural development. Participation: The new tyranny, 16-35.

O’Beirne, J. (2016) Cartography Comparison: Google and Apple Maps. [Online] Available from: https://www.justinobeirne.com/cartography-comparison-part-1 [Accessed May 2018]

Pánek, J. (2016). From mental maps to GeoParticipation. The Cartographic Journal, 53(4), 300-307.

Parker, B. (2006). Constructing community through maps? Power and praxis in community mapping. The Professional Geographer, 58(4), 470-484.

Perkins, C. (2007). Community mapping. The Cartographic Journal, 44(2), 127-137.

Potts, J. (2015). The New Time and Space. Palgrave Macmillan.

Robinson, J. (2003). Political geography in a postcolonial context. Political Geography, 22(6), 647-651.

Rundstrom, Robert A. 1998. Mapping, The White Man's Burden. The Common Property Resource Digest (45):1-9.

Sartre, J.P. (1963). Preface. In Fanon, F. (2001). The wretched of the earth. London and New York: Penguin Books.

Shapter, T. (1971). The History of the Cholera in Exeter in 1832. SR Publishers.

Sheehan, M. (2015) The Democratization of GIS. GISCafe [Online] Available from: https://www10.giscafe.com/blogs/mobilegis/2015/02/19/the-democratization-of-gis/ [Accessed March 2015].

Sletto, B. I. (2009). "We Drew What We Imagined" participatory mapping, performance, and the arts of landscape making. Current anthropology, 50(4), 443-476.

Smith, S. (2015) Prefer Typing to Running a Marathon? Take Part in a Mapathon. British Red Cross [Online] Available from: http://blogs.redcross.org.uk/international/2015/10/prefer-typing-to-running-amarathon-take-part-in-a-mapathon/ [Accessed October 2015].

Snow, J. (1855). On the mode of communication of cholera. John Churchill.

Soja, E (1989) Postmodern Geographies: The reassertion of Space in Critical Social Theory. London and New York: Verso Books.

Specht, D. (2017) Lore in the time of Cholera. Maplines. Winter 2017. 
Specht, D. (2018) Neogeography, development and human rights in Latin America. in: Raftopoulos, M. and Powęska, R. (eds.) Natural Resource Development and Human Rights in Latin America: State and Non-State Actors in the promotion and opposition to extractivism activities London University of London.

Spivak, G. C. (1988). Can the subaltern speak?. In Marxism and the Interpretation of Culture (pp. 271-313). Macmillan Education UK.

Taylor, M. (2007). Community participation in the real world: opportunities and pitfalls in new governance spaces. Urban studies, 44(2), 297-317.

Thumim, N. (2012). Self-representation and digital culture. Palgrave Macmillan.

Tullis, P. (2015) Can Technology Save Africa's Forests? TakePart [Online] Available from: http://www.takepart.com/feature/2015/06/12/technology-prevent-deforestation/ [Accessed June 2015].

Verplanke, J., McCall, M. K., Uberhuaga, C., Rambaldi, G., \& Haklay, M. (2016). A Shared Perspective for PGIS and VGI. The Cartographic Journal, 53(4), 308-317.

Wainwright, J., \& Bryan, J. (2009). Cartography, territory, property: postcolonial reflections on indigenous counter-mapping in Nicaragua and Belize. cultural geographies, 16(2), 153-178.

Walker, B. B., \& Rinner, C. (2013). A qualitative framework for evaluating participation on the Geoweb. URISA Journal, 25(2), 15-24.

Weiner, D., Harris, T. M., \& Craig, W. J. (2002). Community participation and geographic information systems. Community participation and geographic information systems, 3-16.

Wood, D. (2015) Mapping Deeply. Humanities 4(3), 304-318

Yancy, G. (2008). Colonial Gazing: The Production of the Body as" Other". Western Journal of Black Studies, 32(1), 1. 